Editorial, v.7, n.1 (2019)

\title{
A DISSEMINAÇÃO DA PRODUÇÃO TÉCNICA/TECNOLÓGICA GERADA EM PROGRAMAS STRICTO SENSU PROFISSIONAIS
}

\author{
${ }^{1}$ Cristina Dai Prá Martens \\ ${ }^{2}$ Cristiane Drebes Pedron
}

Em 2019 a IPTEC apresenta algumas mudanças em sua estrutura de editoria. Gostaríamos de iniciar o editorial da $11^{\mathrm{a}}$ edição agradecendo ao trabalho do Prof. Leandro Alves Patah, que muito contribuiu com a revista IPTEC como Editor Chefe, desde a sua criação, em 2013, tendo publicado 10 edições da revista. Sua expertise em Gerenciamento de Projetos também muito contribuiu para o Programa de Pós-Graduação em Gestão de Projetos - PPGP da UNINOVE, contexto onde a IPTEC foi criada e é desenvolvida.

Recentemente, assumimos a editoria da Revista IPTEC com o desafio de dar maior visibilidade a este periódico que tem como missão disseminar a produção intelectual aplicada à prática profissional, nas áreas de inovação, gerenciamento de projetos, desenvolvimento de tecnologias e sustentabilidade. Esse tipo de produção intelectual tem sido gerado especialmente em programas de pós-graduação stricto sensu de caráter profissional, quais sejam os Mestrados Profissionais e os Doutorados Profissionais.

Na Portaria ${ }^{\circ}$ 60, da CAPES, de 20 de março de 2019, encontramos o argumento sobre a importância dos programas de mestrado e doutorado profissional: "a relevância social, científica e tecnológica dos processos de formação profissional avançada, bem como o necessário estreitamento das relações das instituições de ensino e de pesquisa com os diferentes setores públicos e privados de atuação profissional" (Brasil, 2019, p.26). Neste contexto, a CAPES define os seguintes objetivos para os cursos de mestrado e doutorado profissional:

Art. $2^{\circ}$ São objetivos dos cursos de mestrado e doutorado profissionais: I - capacitar profissionais qualificados para práticas avançadas, inovadoras e transformadoras dos processos de trabalho, visando atender às demandas sociais, econômicas e organizacionais dos diversos setores da economia; II - transferir conhecimento para a sociedade de forma a atender às demandas sociais e econômicas, com vistas ao desenvolvimento nacional, regional e local;

III - contribuir para agregação de conhecimentos de forma a impulsionar o aumento da produtividade em empresas, organizações públicas e privadas;

\footnotetext{
${ }^{1}$ Universidade Nove de Julho - UNINOVE, São Paulo, (Brasil). E-mail: cristinadpmartens@ gmail.com Orcid id: https://orcid.org/0000-0003-0955-9786

${ }^{2}$ Universidade Nove de Julho - UNINOVE, São Paulo, (Brasil). E-mail: cdpedron@ gmail.com Orcid id: https://orcid.org/0000-0002-9920-3830
} 
IV - atentar aos processos e procedimentos de inovação, seja em atividades industriais geradoras de produtos, quanto na organização de serviços públicos ou privados;

$\mathrm{V}$ - formar doutor com perfil caracterizado pela autonomia, pela capacidade de geração e transferência de tecnologias e conhecimentos inovadores para soluções inéditas de problemas de alta complexidade em seu campo de atuação.

Esses objetivos remetem ao desafio de aproximar universidade e empresa, na busca por soluções de problemas. Ao mesmo tempo que se deve prezar por um rigor científico e metodológico no desenvolvimento das pesquisas, elas devem ter como foco o campo de aplicação profissional. Dessa forma, problemas que emergem da realidade empresarial devem ser base para a definição de problemas de pesquisa de dissertações e teses profissionais. Em última análise, espera-se que os estudos gerem impacto em contexto profissional aplicado.

Com esse direcionamento, algumas questões surgem: Que tipo de problema tem relevância para ser considerado foco de uma dissertação ou tese? Se o trabalho busca uma solução para problema empresarial, como se definem os limites entre uma dissertação ou tese e um trabalho de consultoria? O que pode ser considerado impacto de uma dissertação ou tese profissional?

Gregor e Havner (2013) nos dão subsídios para responder a essas e outras questões. Em seu estudo sobre uso de Design Science Researh para busca de impacto, eles apresentam um quadrante de contribuições considerando os eixos de maturidades da solução e de domínio de aplicação, ambos variando entre baixo e alto. Quatro segmentos são apresentados:

- Invenção: novas soluções para novos problemas;

- Melhorias: novas soluções para problemas conhecidos;

- Extrapolação: soluções conhecidas aplicadas a novos problemas;

- Rotina: soluções conhecidas para problemas conhecidos.

Desses quatro segmentos, os três primeiros podem ser considerados na geração de problemas de pesquisa em nível de stricto sensu. As pesquisas para a resolução de tais problemas devem ter como ponto de partida a consulta das literaturas científica e técnica (a exemplo de bases de patentes) para levantamento do estado da arte, bem como da literatura 'cinzenta'. A pesquisa de campo pode contemplar, preferencialmente, metodologias de intervenção. Ao final do estudo, espera-se a solução para o problema, a produção intelectual de caráter científico evidenciando a contribuição para a área de conhecimento, e a produção técnica/tecnológica com a relevância para a prática profissional.

A IPTEC se insere no contexto de veículos que visam a publicação das produções intelectuais de caráter técnico/tecnológico, que apresentem contribuições para o meio prático, para o campo de atuação profissional. Foca-se na divulgação do estudo que "privilegia a contribuição de natureza técnica de um trabalho feito com propósitos profissionais, porém com o rigor da pesquisa científica" (Biancolino, Kniess, Maccari, \& Rabechini Jr., 2012, p.294). Motta (2017, p.4) esclarece que a solução de problemas deve ser a abordagem predominante nas produções com ênfase profissional, uma vez 
que a sua divulgação é direcionada não só para estudantes, professores e pesquisadores, mas também (e especialmente) para praticantes.

Para orientar o desenvolvimento desse tipo de produção, o trabalho de Biancolino et al. (2012) apresenta um direcionamento para a elaboração de relato de produção técnica ou artigo tecnológico visando sua divulgação pública, e pode ser adotado com um adequado roteiro. Com base nesse estudo, reforçamos alguns aspectos que devem ser privilegiados nesse tipo de produção:

- Introdução com a apresentação do que se trata o estudo, o problema a ser resolvido/relatado, o objetivo do estudo, como foi feita a pesquisa, qual a intervenção realizada e o que será analisado.

- Fundamentação teórica com apresentação de literatura que permita a compreensão do tema de estudo de modo a enquadrar o trabalho do ponto de vista teórico e propiciar comparações com a teoria existente, bem como dar adequado embasamento teórico à proposta de intervenção.

- Método que descreva a escolha metodológica de forma fundamentada e coerente com o objetivo do relato técnico/artigo tecnológico. Apresentação do tipo de intervenção e mecanismos adotados, das técnicas utilizadas para coleta e análise dos dados, com o devido detalhamento dos procedimentos realizados.

- Análise dos resultados que envolva a caracterização da organização e do problema no contexto investigado, apresente a intervenção desenvolvida com descrição das atividades realizadas para solucionar o problema, a descrição dos resultados obtidos e sua análise considerando-se também a literatura de base

- Conclusão e contribuições, com a evidenciação de que os objetivos inicialmente propostos foram atingidos. Devem ser apresentadas as contribuições do estudo para a prática profissional e para a área de conhecimento, os aprendizados decorrentes do estudo, bem como a relevância para outros casos similares. Devem ser mencionados os aspectos que limitaram o trabalho e sugestão de novos estudos.

Queremos motivar estudantes e professores, especialmente de programas stricto sensu profissionais, a evidenciarem esse tipo de produção intelectual que tem como objetivo a geração de impacto no ambiente prático. Esperamos que essas orientações possam facilitar, e mesmo motivar, a apresentação dos resultados dos estudos desenvolvidos em contexto de prática profissional.

Poucos são os periódicos no Brasil que possuem esse enfoque, e grande é o desafio de se produzir artigos com esse caráter de aplicabilidade, sem deixar de lado o rigor científico. A Revista IPTEC está aberta a submissão de trabalhos com essa abordagem, com o desejo de divulgar estudos que propiciem contribuições para o contexto prático-profissional, especialmente nas áreas de gestão de projetos, inovação, sustentabilidade e desenvolvimento tecnológico.

\section{Referências}

Biancolino, C. A., Kniess, C. T., Maccari, E., \& Rabechini Jr, R. (2011). Protocolo para elaboração de relatos de produção técnica. Revista de Gestão e Projetos - GeP, 3(2), 294-307. 2019.

Brasil (2019). Diário Oficial da União, Seção 1. Brasília - DF, nº 56, sexta-feira, 22 de março de

Gregor, S., \& Hevner, A. R. (2013). Positioning and presenting design science research for maximum impact. MIS Quarterly, 37(2), 337-355.

Motta, G. D. S. (2017). Como escrever um bom artigo tecnológico? Revista de Administração Contemporânea, 21(5), 4-8.

Revista Inovação, Projetos e Tecnologias | v.7 | n.1 | Editorial | Jan/Jun 2019. 